\title{
ROAD TRAFFIC ACCIDENTS AMONG BUS DRIVERS
}

\author{
By \\ El Safty A.*, Fayek E.**, Samir A.*, Shaker D.* \\ From \\ *Department of Industrial Medicine and Occupational Diseases \\ Faculty of Medicine,Cairo University \\ **NECTR ,Faculty of Medicine,Cairo University
}

\begin{abstract}
:
Background: Every day thousands of people are killed or injured on our roads, leaving behind shattered families and communities. Current efforts to address road safety are incomparable to the growing human suffering. One of the most important risk factors for road traffic injuries, is drug abuse. Objectives: Our research team was assigned by one of the largest factories in Egypt to address this problem after recording several accidents during 2007 year, and to determine the role of drugs as a causal factor in traffic crashes. Methods: All the bus drivers employed in this factory were enrolled in this study. A group of referents $(n=20)$ were randomly taken from workers employed in the same factory. Urine samples were collected in the presence of one of our paramedics. Drugs screened were the major drugs of abuse such as Cannabinoids (marijuana, hashish), Benzodiazepines (e.g., Valium) and Barbiturates. An enzyme-linked immunosorbent assay was conducted for opiates (morphine, codeine), amphetamines, cannabinoids, benzodiazepines and cocaine. Gas chromatography-mass spectrometry analysis (GCMS) was used for estimation of antidepressants, methadone, other analgesics and a number of anticonvulsants, benzodiazepines.
\end{abstract}

Results: Thirty two specimens were analyzed. Metabolites of cannabis were the most commonly detected drugs and were found in 7 cases $(21.8 \%)$, followed by benzodiazepines in 2 cases $(6.3 \%)$ and opiates in 2 cases $(6.3 \%)$. Thirteen Drivers (41.9\%) had at least one accident per year. Also it was found that the incidence of car accidents is higher among younger age groups. There is a statistically significant positive association between smoking and drug abuse. Statistically significant positive correlation was demonstrated between experiencing abnormal psychological behaviours and positive drug abuse. Conclusion: Drug usage found in the studied group of drivers was disturbingly high. The introduction of further initiatives to decrease the prevalence of drug use in motor vehicle drivers is required; however, a follow-up study is needed. The magnitude of this problem has to be studied on a large scale. We recommend preemployment and periodic drug screening for all professional car drivers for safer work practice. Random urine screening for drugs, should also be carried out specially for those who drive on highways. 


\section{Introduction}

Road traffic injuries are a growing public health and development problem. The majority of car accidents are caused by irresponsible driving behavior. Forty percent of all car accidents in the U.S. are related to DWI (driving while impaired), usually involving drugged drivers. Speeding and drugged drivers are major causes of accidents.The number of road traffic injuries and deaths has shown an overall downward trend in high-income countries since 1970s and an increase in the low-income and middle income countries. Road traffic injuries are predicted to rise from the tenth place in 2002 to the eight place in 2030, as a contributor to the global burden of disease. Road traffic deaths are predicted to increase by $83 \%$ in low income and middle income countries and to decrease by $27 \%$ in high income countries. The overall global increase is predicted to be $67 \%$ by 2020 if appropriate action is not taken (WHO, 2006).

The World Health Organization and the World Bank have jointly produced a world report on road traffic injury prevention, to present a comprehensive overview of what is known about the magnitude, risk factors and impact of road traffic injuries and about ways to prevent and decrease the impact of road crashes (WHO, 2006).
Current efforts to address road safety are incomparable to the growing human suffering. Despite this, very little is known about how often drivers consume drugs during driving, what drugs are involved and how drugs affect the incidence of road trauma. There is increasing inter-interest throughout the world concerning the incidence of drug abuse among drivers in driving and their contribution to road trauma specifically. Until now, studies of drugs and driving have focused on fatal collisions (Ch'ng et al., 2007).

According to the Transport research laboratory (2007) the role of drugs as a causal factor in traffic crashes involving drug-positive drivers is still not understood. Drug risk factors are still not known with acceptable precision, with some evidence suggesting little or no increase in crash risk at drug levels being detected by current chemical test procedures. Available evidence suggests a maximum risk factor of about 2.0 occurring for benzodiazepines and cannabis, followed closely by narcotics at 1.5 . CNS stimulants (including cocaine and amphetamines) were associated with either no increased risk factor (cocaine) or even a decreased risk factor (other stimulants).

\section{Aim of the work}

In Egypt little is known about the caus- 
al factors of car accidents. Safety on the job and the safety of the public is perhaps the most compelling concern that has driven our research team to conduct this work. The main aim of this work was to determine the role of drugs as a causal factor in traffic crashes among bus drivers employed in one of the major steel companies in Egypt.

\section{Subjects and methodology}

Our research team was assigned by one of the largest steel mills in Egypt to address this problem after recording several accidents during the year 2007. All the bus drivers employed in this factory were enrolled in this study. A total of 32 drivers were screened for drug abuse after getting involved in repeated traffic accidents threatening lives of factory workers and the public. A visit to the factory was planned by our research team. All subjects were personally interviewed and filled a questionnaire concerning possible involvement with drugs during the past 12 months.

A group of referents $(n=20)$ were randomly taken from workers employed in the same factory. Both groups were matched in age, sex and socioeconomic standard. History and full clinical examination were performed to detect manifestations of drug abuse. Urine samples were collected in the presence of one of our paramedics. Drugs screened for the major drug of abuse such as Cannabinoid (marijuana, hashish), Benzodiazepines (e.g., Valium) and Barbiturates. An enzyme-linked immunosorbent assay was conducted for opiates (morphine, codeine), amphetamines, cannabinoids, benzodiazepines and cocaine.

Gas chromatography-mass spectrometry analysis (GC-MS) was used to estimate targeted antidepressants, methadone and other analgesics, stimulants, a number of antipsychotics and numbers of anticonvulsants, and benzodiazepines drugs. Using 1-ml plasma samples, allowed for the detection of most drugs, sample preparation for GC-MS involved basification of plasma then extraction using n-butyl chloride followed by concentration to dryness and reconstitution in toluene for chromatography. Methods allowed for the detection of most drugs in concentrations $>0.02 \mathrm{mg} / \mathrm{L}$ including morphine and codeine. While the threshold detection limits for methamphetamine, benzoyl ecgonine (cocaine metabolite) and THC tetrahydrocannabinol were $0.05,0.05$ and $0.002 \mathrm{mg} / \mathrm{L}$ respectively. (Drummer et al., 1994).

\section{Statistical analysis}

The statistical evaluation of the results was conducted with use of the software statistical package for social sciences (SPSS) 
for windows 16 program. A $\mathrm{P}$ value of $<0.05$ was considered significant.

\section{Results}

This work was conducted on 32 male bus drivers, their age range was 21-55

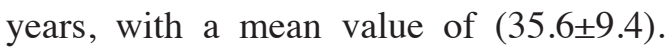
The drivers' group had a mean duration of employment of $7.0 \pm 5.37$ years. Both studied groups were statistically matched as regards age, and marital status. Twenty subjects among the driver groups $(62.5 \%)$ were cigarette smokers and 11 subjects (34\%) reported to be drug abusers (table 1). Laboratory urine screening for drugs detected 7 subjects $(21.8 \%)$ positive for cannabinoids, 2 subjects $(6.3 \%)$ positive for benzodiazepines and 2 other subjects (6.3\%) positive for opiates. It was found also that the incidence of car accidents was 8 out 13 accidents $(61.5 \%)$ among age group from 25-34, 4 out of 13 accidents among age group 35-44 (30.7\%)and only one accident out of 13(7.6\%) among age group of 45 and above.

General manifestations of drug abuse including psychoneurotic manifestations were studied among the examined groups and abnormal behaviour in the form of repeated un-explained absenteeism from work was detected in 2 cases $(6.25 \%)$, frequent troubles with colleagues in 4 cases $(12.5 \%)$, nervousness in 4 cases (12.5\%), changes in sleep pattern in 2 subjects $(6.25 \%)$, slurred speech in only one case $(3.13 \%)$, tremors in 2 cases $(6.25 \%)$, blood shot eye in 12 cases $(37.5 \%)$, and poor hygiene in 3 cases $(9.38 \%)$. None of the control group has abnormal psychoneurotic manifestations.

Table (3) shows that 13 drivers (41.9\%) had at least one accident per year, 11 of them were positive for urine screening test and only 2 were negative. This indicates that the incidence of car accident is significantly higher among driver positive for drug abuse. The drivers that had more than one accident per year were positive for cannabinoids.

The relation between drivers with positive drug abuse and smoking habits was shown in table (4), there is a statistically significant higher percentage of smokers among drivers that have positive drug abuse.

Table (5) and (6) show that the percentage of accidents and abnormal behaviour were statistically significantly higher among drivers positive for drug abuse. 
Table (1) Demographic characteristics of the studied groups:

\begin{tabular}{|l|c|c|c|}
\hline General characteristics & Drivers (no.=32) & Control (no.=20) & P value \\
\hline Marital Status & $27(84 \%)$ & $16(80 \%)$ & $>0.05$ \\
\hline Smoking habit & $20(62.5 \%)$ & $4(20 \%)$ & $<0.005$ \\
\hline Drug abuse & $11(34 \%)$ & $0(0 \%)$ & $<0.001$ \\
\hline
\end{tabular}

Table (2) Prevalence of behavioural changes among the professional driver's groups:

\begin{tabular}{|l|cc|}
\hline & \multicolumn{2}{|c|}{ Drivers } \\
& No. $\%$ \\
\hline Absenteeism from work & 2 & 6.25 \\
\hline Troubles with colleagues & 4 & 12.5 \\
\hline Nervousness & 4 & 12.5 \\
\hline Slurred speech & 1 & 3.13 \\
\hline Tremor & 2 & 6.25 \\
\hline Changes in sleep pattern & 2 & 6.25 \\
\hline Blood shot eye & 12 & 37.5 \\
\hline Poor hygiene & 3 & 9.38 \\
\hline
\end{tabular}


Table (3) Accidents Prevalence among the studied groups:

\begin{tabular}{|l|cc|cc|c|}
\hline & \multicolumn{2}{|c|}{ Drivers (no=32) } & \multicolumn{2}{|c|}{ Control (no=20) } & \multirow{2}{*}{ P value } \\
\hline History of car accident & 13 & $(40.6 \%)$ & 1 & $(5 \%)$ & 0.005 \\
\hline One accident/year & 7 & $(21.9 \%)$ & 1 & $(5 \%)$ & $<0.05$ \\
\hline Two accidents/year & 4 & $(12.5 \%)$ & 0 & $(0 \%)$ & ----- \\
\hline More than two/accidents/year & 2 & $(6.2 \%)$ & 0 & $(0 \%)$ & ---- \\
\hline
\end{tabular}

Table (4): Relation between drug abuse and smoking habits:

\begin{tabular}{|c|c|c|c|c|}
\hline \multirow{2}{*}{ Smoking } & \multicolumn{5}{|c|}{ Drug abuse } \\
\cline { 2 - 6 } & \multicolumn{2}{|c|}{$\begin{array}{c}\text { NO } \\
(\mathrm{n}=21)\end{array}$} & \multicolumn{2}{c|}{$\begin{array}{c}\text { YES } \\
(\mathrm{n}=11)\end{array}$} \\
\cline { 2 - 6 } & $\mathrm{n}$ & $\%$ & $\mathrm{n}$ & $\%$ \\
\hline NO (n=12) & 11 & 52.4 & 1 & 90.1 \\
\hline YES (n=20) & 10 & 47.6 & 10 & \\
\hline$\chi^{2}$ & \multicolumn{5}{|c|}{5.77} \\
\hline P-value & \multicolumn{5}{|c|}{0.016} \\
\hline
\end{tabular}


Table (5): Relation between drug abuse and frequency of accidents.

\begin{tabular}{|c|c|c|c|c|}
\hline \multirow{3}{*}{ Accidents } & \multicolumn{4}{|c|}{ Drug abuse } \\
\hline & \multicolumn{2}{|c|}{$\begin{array}{c}\text { NO } \\
\text { (no.=21) }\end{array}$} & \multicolumn{2}{|c|}{$\begin{array}{c}\text { YES } \\
\text { (no.=11) }\end{array}$} \\
\hline & $\mathrm{n}$ & $\%$ & $\mathrm{n}$ & $\%$ \\
\hline $\begin{array}{c}\text { NO } \\
(\text { no. }=19)\end{array}$ & 16 & 84.2 & 3 & 15.8 \\
\hline $\begin{array}{c}\text { YES } \\
\text { (no.=13) }\end{array}$ & 5 & 38.5 & 8 & 61.5 \\
\hline$\chi^{2}$ & \multicolumn{4}{|c|}{7.11} \\
\hline $\mathrm{P}$-value & \multicolumn{4}{|c|}{0.017} \\
\hline
\end{tabular}

Table (6): Relation between drug abuse and behavioural changes.

\begin{tabular}{|c|c|c|c|c|}
\hline \multirow{3}{*}{ Abnormal behaviour } & \multicolumn{4}{|c|}{ Drug abuse } \\
\hline & \multicolumn{2}{|c|}{$\begin{array}{c}\text { NO } \\
(\text { no. }=21)\end{array}$} & \multicolumn{2}{|c|}{$\begin{array}{c}\text { YES } \\
(\text { no.=11) }\end{array}$} \\
\hline & $\mathrm{n}$ & $\%$ & $\mathrm{n}$ & $\%$ \\
\hline $\begin{array}{c}\text { NO } \\
(n=24)\end{array}$ & 19 & 79.2 & 5 & 20.8 \\
\hline $\begin{array}{c}\text { YES } \\
(\mathrm{n}=8)\end{array}$ & 2 & 25 & 6 & 75 \\
\hline$\chi^{2}$ & \multicolumn{4}{|c|}{7.80} \\
\hline P-value & \multicolumn{4}{|c|}{0.005} \\
\hline
\end{tabular}




\section{Discussion}

Deaths from injuries are projected to rise from 5.1 million in 1990 to 8.4 million in 2020 with increase in road traffic injuries as a major cause for this rise. Currently deaths from road traffic injuries account for $2.2 \%$ of the global mortality affecting all age groups. Road traffic injuries place a heavy burden, not only on global and national economies but also on household finances. Many families are driven deeply into poverty by the loss of breadwinners and the added burden of caring for members disabled by road accidents (WHO, 2006).

Our findings showed a statistically significantly higher percentage of cigarette smokers among drivers compared with the control group table (1). This may imply that smoking habit is the first step for drug abuse as revealed by the relation demonstrated in our work (table 4). This is in agreement with Ryb et al. (2007), who reported that smokers had higher rate of drug dependence than non-smokers and were more likely to have repeated history of prior vehicular or assault trauma within the vehicular trauma population.

Statistically significant increase in the number of car accidents among drivers who were positive for drug abuse was revealed in our work, compared to those who were not drug abusers. This is in agreement with Mura et al. (2003) who demonstrated a higher prevalence of opiates and cannabinoids in blood samples from drivers involved in road accidents, which suggested a causal role for these compounds in road crashes. Also, Movig et al. (2004), in their case control study conducted over one year from May 2000 to August 2001, in which urine samples were collected from drivers involved in road crashes needing hospitalization and were tested for licit and illicit drugs, they reported that drug use, among vehicle drivers increased the risk for a road trauma accident requiring hospitalization. Our findings also were consistent with Giovanaroli et al. (2005), who confirmed that there was a significant percentage of injuryproducing traffic crashes involving drivers who were under the influence of drugs of abuse or other drugs affecting the CNS.

This was also consistent with the results of a survey conducted by Cheng et al. (2005) between 1996 and 2000, in which a total of 197 fatal traffic crash cases of drivers were investigated for the presence of drugs. The authors reported that a driver consuming drugs had a higher risk of being involved in a fatal vehicle crash. This is explained by the fact that these drugs act on the brain and can alter perception, cog- 
nition, attention, balance, coordination, and other faculties required for safe driving.

Other studies showed lack of a clear relationship between accidents and drug abuse among drivers involved in road accidents. Pelissier et al. (1996) did not show any differences between drug abusing young adults involved in road accident using opiates, cannabinoids, cocaine and amphetamine and a control group.

This may be due to the high prevalence of drug abuse among young adults in European countries.

In our study, there was a significant relation between drug abuse and behavioural changes detected in our surveyed group (table 6). This may be due to the fact that these drugs cause increased energy, rapid heart rate and elevated blood pressure, but they also produce racing thoughts and make the driver feel overly-stimulated. Continued use causes rapid breathing, irritability, impulsiveness, aggression, nervousness, insomnia, weight loss, tolerance, addiction, and possible heart failure. These drugs also cause an impairment in cognitive functioning which negatively affects memory and impacts the ability to learn.

A meta-analysis of approximately 60 experimental studies, including laboratory, driving simulator, and on-road experiments, found that behavioural and cognitive skills related to driving performance were impaired in a dose-dependent fashion with increasing tetrahydrocannabinol (THC) blood levels (Berghaus et al.,1995).

Drug abuse and addiction have a devastating impact on society costing billions of dollars each year. Drug abuse is responsible for decreased job productivity and attendance, increased healthcare costs, and an escalation of domestic violence and violent crimes. Our work detected that $21.8 \%$ of the drivers' group were positive for cannabinoids, $6.3 \%$ positive for benzodiazepines and $6.3 \%$ positive for opiates. Large study of almost 3,400 fatally injured drivers from three Australian states (Victoria, New South Wales, and Western Australia) between 1990 and 1999 proved that drugs other than alcohol were present in 26.7 per cent of the cases. These included cannabis (13.5\%), opioids (4.9\%), stimulants (4.1 $\%)$, benzodiazepines (4.1\%), and other psychotropic drugs $(2.7 \%)$. Almost 10 percent of the cases involved both alcohol and drugs (Drummer et al., 2003).

Many researches indicated that marijuana was the most prevalent illegal drug detected in impaired drivers, fatally injured drivers, and motor vehicle crash victims. Studies conducted in several localities have found that approximately 4 to 14 per cent 
of drivers who sustained injury or died in traffic accidents tested positive for delta9-tetrahydrocannabinol (THC), the active ingredient in marijuana (Ramaekers et al., 2004).

Evidence from both real and simulated driving studies indicated that marijuana can negatively affect a driver's attentiveness, perception of time and speed, and the ability to draw on information obtained from past experiences (NIDA, 2008).

Both experimental and epidemiological studies have demonstrated the negative effects of THC upon cognitive functions and psychomotor skills. Culpability studies have recently demonstrated an increased risk of becoming responsible in fatal or injurious traffic accidents, even with low blood concentrations of THC. It has also been demonstrated that there is a correlation between the degree of impairment, the drug dose and the THC blood concentration (Khiabani et al. 2007).

Delta-9-tetrahydrocannabinol (THC) displays an exceptional lipophilicity, allowing its cerebral storage, leading to long lasting effects; by far more lasting than its presence in blood, and beyond the period throughout the intoxicated people feel a disablement. This is linked to its slow release from brain areas in which large pro- portion of spare receptors exists (reserve receptors). THC disturbs cognition and various skills required in driving. It may be responsible for psychiatric troubles: anxiety, depression, suicide attempt, psychotic attack and triggering of schizophrenia. It potentiates the alcohol effects and incites to alcohol drinking. It displays close relationships with dependence to heroin. This new landscape of cannabis urges to make a radical alteration in the public communication about this drug of abuse as it has yet caused so many troubles, accidents or tragedies (Costentin, 2006).

Our results revealed that there was increased incidence of car accidents among younger drivers. This can be explained by the fact that driving under the influence of an illicit drug or alcohol was associated with age. In 2006, an estimated 7.3 per cent of youth aged 16 years drove under the influence of drugs. This percentage steadily increased with age to reach a peak of 31.8 per cent among young adults aged 22 years. Beyond the age of 22, these rates showed a general decline with increasing age (Substance Abuse and Mental Health Services Administration, 2006).

According to the National Highway Traffic Safety Administration (2007), vehicle accidents are the leading cause of death among young people aged 16 to 20 years. 
It is generally accepted that young drivers have less experience and they have a higher risk of being involved in an accident compared with more experienced drivers. When this lack of experience is combined with the use of marijuana or other substances that impact cognitive and motor abilities, the results can be tragic.

\section{Conclusion}

We conclude that causal risk factors that lead to accidents among drivers in this factory are smoking habits entangled with drugs of abuse mainly cannabinoids; however, a follow-up study is needed. The magnitude of this problem has to be studied on large scale.

\section{Recommendation}

In an attempt to reduce road traffic accidents we recommend pre-employment and periodic drug screening for all professional car drivers for safer work practice. Random urine screening for drugs, should also be carried out specially on highways.

\section{References}

1. Berghaus G, Sheer N, Schmidt P (1995): Effects of cannabis on psychomotor skills and driving performance. Meta-analysis of experimental studies. In: kloeden $\mathrm{CN}$ and McLean AJ, eds. Proceedings of the 13th International Conference on Alcohol, Drugs and Traffic Safety. Adelaide, Australia: The University of Adelaide, NHMRC Road Accident Research Unit, pp. 403- 409.
2. Ch'ng CW, Fitzgerald M, Gerostamoulos J, Cameron P, Bui D, Drummer O, Potter J and Odell M (2007): Drug use in motor vehicle drivers presenting to an Australian, adult major trauma centre. Emerg. Med. Austr.J. 19(4):359-65.

3. Cheng JY, Chan DT and Mok VK (2005): An epidemiological study on alcohol/drugs related fatal traffic crash cases of drivers in Hong Kong between 1996 and 2000. Forensic Sci Int. 153 (2-3): 196- 201.

4. Costentin J (2006): Neurology of cannabis-- recent data enlightening driving disturbances. Ann Pharma Fr. 64(3): 148-59.

5. Drummer OH, Horomidis S, Kourtis S, Syrjanen ML, Tippett P (1994): Capillary gas chromatographic drug screen for use in forensic toxicology. J. Anal. Toxicol. 18: 134-8.

6. Giovanardi D, Castellana CN, Pisa S, Poppi B, Pinetti D, Bertolini A and Ferrari A (2005): Prevalence of abuse of alcohol and other drugs among injured drivers presenting to the emergency department of the University Hospital of Modena, Italy. Drug Alcohol Depend. 80(1): 135-8.

7. Khiabani HZ, Christophersen AS and Morland J (2007): Cannabis affects driving skills. Tidsskr Nor Laegeforen. 127 (5): 583-4.

8. Movig KL, Mathijssen MP, Nagel PH, van Egmond T, de Gier JJ, Leufkens HG and Egberts AC (2004): Psychoactive substance use and the risk of motor accidents. Acid Anal Prev. 36 (4): 631-6.

9. Mura P, Kintz P, Ludes B, Gaulier JM, Marquet P, Matin-Dupont S, Vincent F, Kaddour A, Goulle JP, Nouveau J, Moulsma M, Tilhet-Coartet S and Pourrat O (2003): Comparison of the prevalence of alcohol, cannabis and other drugs between 900 injured drivers and 900 control subjects: results 
of a French collaborative study. Forensic Sci Int. 133 (1-2): 79-85.

10. National Highway Traffic Safety Administration (2007): Traffic Safety Facts Research Note. Washington, DC. U.S. Department of Transportation Report No. DOT HS 810821.

11. National Institute of Drug Abuse (2008): NIDA InfoFacts, Drugged Driving. National Institute On Drug Abuse. www.drugabuse.gov.

12. Pelissier AL, Leonetti G, Kerguelen S, Bremond J, Botta A, Cianfarani F and Garnier M (1996): Urinary screening of drugs of abuse among drivers involved in road accidents. Ann Biol Clin (Paris). 54 (10-11): 365-71.

13. Ryb GE, Dischinger P, Kufera $\mathbf{J}$ and Soderstrom C (2007): Smoking is a marker of risky behavior independent of substance abuse in injured drivers. Traffic Inj Prev. Sep; 8 (3): 248-52.

14. Ramaekers JG, Berghaus G, van Laar M and Drummer OH (2004): Dose related risk of motor vehicle crashes after cannabis use. Drug Alcohol Depend. 73 (2): 109-19.

15. Substance Abuse and Mental Health Services Administration (2006): National Survey on Drug Use and Health. Rockville, MD.

16. Transport research laboratory (2007): The good, the bad and the talented: young driver's perspectives on good driving and learning to drive.

17. World health organisation (2006): (http://www. who.int/world-health-ay/previous/2004/en/traffic_facts_en.pdf). 